\title{
Fear-avoidance beliefs are associated with exercise adherence: secondary analysis of a randomised controlled trial (RCT) among female healthcare workers with recurrent low back pain
}

Annika Taulaniemi ${ }^{1 *}$ (D), Markku Kankaanpää2 ${ }^{2}$, Marjo Rinne ${ }^{1}$, Kari Tokola', Jari Parkkari ${ }^{1}$ and Jaana H. Suni ${ }^{1}$

\begin{abstract}
Background: Exercise is recommended for the treatment and management of low back pain (LBP) and the prevention of chronicity. Exercise adherence has been only modest in intervention studies among people with musculoskeletal pain. Fear-avoidance beliefs (FABs) are known to affect exercise adherence.

The purpose was twofold: to examine which bio-psycho-social factors contributed to exercise adherence during a 6-month neuromuscular exercise intervention among female healthcare workers with recurrent LBP, and to investigate how exercising affects FABs at 6 and 12 months' follow-up.
\end{abstract}

Methods: Some 219 healthcare workers aged 30-55 years with mild-to-moderate re-current non-specific LBP were originally allocated into: 1) exercise, 2) counselling, 3) combined exercise and counselling, and 4) control groups. In the present secondary analysis, groups 1 and 3 (exercise only and exercise+counselling) were merged to be exercisers and groups 2 and 4 were merged to be non-exercisers. Baseline variables of the exercise compliers $(\geq 24$ times over 24 weeks; $n=58$ ) were compared to those of the non-compliers ( $<1$ time/week, $0-23$ times; $n=52)$. The effects of the exercise programme on FABs were analysed by a generalised linear mixed model according to the intention-to-treat principle (exercisers; $n=110$ vs non-exercisers; $n=109$ ) at three measurement points (baseline, 6 , and 12 months). A per-protocol analysis compared the more exercised to the less exercised and non-exercisers.

Results: A low education level $(p=0.026)$, shift work $(p=0.023)$, low aerobic $(p=0.048)$ and musculoskeletal $(p=$ $0.043)$ fitness, and high baseline physical activity-related FABs $(p=0.019)$ were related to low exercise adherence. The exercise programme reduced levels of both physical activity- and work-related FABs, and there was a dose response: FABs reduced more in persons who exercised $\geq 24$ times compared to those who exercised $0-23$ times.

\footnotetext{
* Correspondence: annika.taulaniemi@ukkinstituutti.fi

${ }^{1}$ UKK Institute for Health Promotion Research, Tampere, Finland

Full list of author information is available at the end of the article
}

(c) The Author(s). 2020 Open Access This article is licensed under a Creative Commons Attribution 4.0 International License, which permits use, sharing, adaptation, distribution and reproduction in any medium or format, as long as you give appropriate credit to the original author(s) and the source, provide a link to the Creative Commons licence, and indicate if changes were made. The images or other third party material in this article are included in the article's Creative Commons licence, unless indicated otherwise in a credit line to the material. If material is not included in the article's Creative Commons licence and your intended use is not permitted by statutory regulation or exceeds the permitted use, you will need to obtain permission directly from the copyright holder. To view a copy of this licence, visit http://creativecommons.org/licenses/by/4.0/. The Creative Commons Public Domain Dedication waiver (http://creativecommons.org/publicdomain/zero/1.0/) applies to the data made available in this article, unless otherwise stated in a credit line to the data. 


\begin{abstract}
(Continued from previous page)
Conclusion: Healthcare workers who had lower education and fitness levels, worked shifts, and had high physical activity-related FABs had a lower adherence to the 6-month neuromuscular exercise programme. Exercising with good adherence reduced levels of FABs, which have been shown to be linked with prolonged LBP. Motivational strategies should be targeted at persons with low education and fitness levels and high FABs in order to achieve better exercise adherence.
\end{abstract}

Keywords: Exercise compliance, Neuromuscular exercise, Pilates, Fear of pain, Lumbar pain, Exercise intervention study, Nursing

\section{Background}

Low back pain (LBP) is common among people in all ages, but disability from LBP is highest in working-age groups [1]. Among healthcare workers, LBP is the leading musculoskeletal disorder [2] and it has been reported to be the most costly and common self-reported disease [3]. Major contributors to the high incidence of LBP among healthcare workers are physically heavy nursing duties, such as lifting and transferring patients, and working in awkward positions $[2,4,5]$.

In physically demanding work duties, maintaining a healthy back requires adequate aerobic and musculoskeletal fitness level [6-8]. Low ratings of self-reported physical capacity have been shown to be a predictor for future LBP in female healthcare workers [9]. Female nurses with a recent back injury also show more impairment in lumbar movement control [10], which has also been suggested to play an important role in maintaining a healthy back $[11,12]$. A systematic review on efficacy of interventions for LBP in nursing personnel [13] revealed no strong evidence of efficacy for any intervention in preventing or treating LBP in healthcare workers.

Exercise is the most often recommended treatment for increasing fitness levels [14], lumbar movement control [12], and for the management and prevention of LBP [15-19]. Thus, in the management of spinal pain exercise adherence is important to realise the beneficial effects of exercising. Adherence is a key link between the process and outcome of exercise interventions among people with musculoskeletal pain, and poor exercise adherence compromises the effectiveness of treatment [20].

Barriers to exercise adherence, such as pain with exercise [21], fear of movement and pain aggravation [22], low selfefficacy [21], psychological dysfunction [21], poor social support [21], lack of time [23], and uncertainty about the benefits of exercise [24], have been reported among people with musculoskeletal pain [21, 22, 24, 25]. Aforementioned studies have been conducted among older adults [25], people with chronic LBP [26] or other chronic musculoskeletal pain [22, 24] or among people receiving physiotherapy [21]. To our knowledge, similar studies which concern exercise adherence among people with heavy physical work and non-chronic LBP have not been conducted.
Fear avoidance is the belief that activities should be avoided to reduce pain [27]. Fear of pain develops as a result of a cognitive interpretation of nociseption as something threatening, and this fear affects attention processes (hypervigilance) and leads to the avoidance of behaviours, like physical activity and exercise, which are expected to cause pain [27]. Fear-avoidance beliefs (FABs) influence treatment effects and are prognostic to poor outcomes in subacute LBP [28]. Cognitive behavioural therapy is recommended to reduce FABs among people with LBP $[29,30]$, but effects of exercise interventions on FABs among people with sub-acute or recurrent LBP are less clear.

Besides FABs, there are probably several other internal factors (like a lack of interest [31], and low self-efficacy [32]) that compromise adherence to exercise among people with LBP. Exercise might be avoided, because it is believed to cause pain, one is uncertain about the benefits of exercising, and one's capabilities to perform and manage the instructed exercises [32]. If those internal factors are combined with external barriers (like lack of time, environment, and transfer), exercise adherence might be challenging.

Among people with chronic LBP, improvements in physical functioning are more strongly associated with adherence to exercise than with the type of exercise [26]. Some $50-70 \%$ of people with chronic LBP are nonadherent to prescribed home exercise [33]. Thus, factors associated with adherence to exercise in LBP require more investigation [33]. Exercise adherence among people with musculoskeletal pain in general is a poorly studied subject [20].

In a previously reported study, we found that a 6month modified Pilates-type neuromuscular exercise intervention, which focused on controlling the neutral lumbar spine posture and developing the muscle strength and endurance needed in heavy nursing tasks, was effective in reducing lumbar pain and lumbar movement control impairments among a sample of nursing personnel with sub-acute or recurrent LBP [34]. In the 6-month intervention, the target was to exercise twice a week, i.e. 48 times in 24 weeks. Exercise adherence was only modest; the mean attendance rate was 26.1 (of the 
targeted 48). The reduction of LBP intensity and lumbar movement control impairment was significantly better in those who exercised once a week or more compared to the less exercised and non-exercisers [34]. Thus, factors affecting exercise adherence needed more investigation. Our hypothesis was that pain intensity, psychological, and environmental factors compromise exercise adherence, and that the modified Pilates-type exercise reduces FABs-PA.

The purpose of this study was to (1) investigate the effects of baseline bio-psychosocial factors on exercise adherence among female healthcare personnel with subacute or recurrent LBP. Furthermore, we sought to (2) examine the effects of the exercise intervention on the development of FABs over time (at 6 and 12 months' follow-up).

\section{Methods}

\section{Study design}

This study is based on the data of a four-arm randomised controlled trial (RCT) among female healthcare personnel (NURSE-RCT, clinical trial registration NCT01465698) [35], in which healthcare personnel with sub-acute or recurrent LBP were randomised to participate in neuromuscular exercise/non-exercise and to receive/not receive back care counselling for 6 months [36]. In the secondary analysis, those receiving exercise (combined exercise + counselling, and exercise only) were merged to be exercisers, and non-exercisers (counselling only and controls) were merged to be the controls [34].

The study was conducted in the form of three identical consecutive sub-studies. The participants were female healthcare workers in physically demanding duties: in old people's homes and geriatric wards (in the first substudy in 2011, $n=56$ ); in home service, public healthcare units, and community hospital wards (in the second sub-study in 2012; $n=80$ ); and in university hospital wards (in the third sub-study in 2013; $n=83$ ) in the city of Tampere, Finland. The protocol and time frame of each sub-study are presented in the study protocol [35]. The recruitment of participants, eligibility criteria, and reasons for exclusion have been previously described in detail [36]. Briefly, 30-55-year-old female healthcare workers were eligible if they had worked in their current job for at least 12 months and had experienced LBP of an intensity of 2 or above on a numeric rating scale (NRS; 0-10) [37] during the previous 4 weeks. The exclusion criteria were a specific or serious earlier back condition (disc protrusion, fracture, surgery), chronic LBP (pain duration $\geq 7$ months), pregnancy or recent delivery ( $<12$ months), and engagement in a neuromuscular-type exercise (NME) more than once a week.
The power calculations, recruitment process, randomisation, and ethical issues of the NURSE-RCT have been presented previously [35], as have the contents of the exercise intervention [34].

The study design and flow of the participants are shown in Fig. 1.

\section{Participants}

The participants were female healthcare workers who engaged in physically demanding work (including lifting, patient transfer and working in awkward positions) and suffered from sub-acute or recurrent LBP. The mean age of the participants was 46 years, and they had worked in their current job on average for 11 years [7]. Some $87 \%$ were nurses or nursing assistants, and $70 \%$ did shift work [7]. In the pre-study screening, most of the study subjects (82\%) experienced LBP on a few or most days of the week, but not daily, while $18 \%$ had LBP daily [7]. At the baseline, the mean of the pain intensity measured on a visual analogue scale (VAS; 0-100) [38] during the previous 4 weeks was 36.2 (SD 22.6) [7]. The majority (77\%) of the study sample can be described as having sub-acute, mild-to-moderate, recurrent or fluctuating non-specific LBP (4). Among those with daily pain $(18 \%)$, the pain intensity was higher the mean in VAS being 55.7 (25.3).

\section{Measurements}

A wide range of measurements was taken at the baseline. In addition to background factors (age, education level, marital status, occupation, number of working years in the current job, working hours, smoking, perceived health and perceived fitness in comparison to persons of the same age and gender, current use of medication, high blood pressure (yes/no), and hormonal status); LBP intensity (VAS; 0-100) during the previous 4 weeks [38]; the frequency of LBP; the number of musculoskeletal pain sites [7]; quality of life (RAND 36) with eight subscales [39, 40]; depression (using the modified Finnish version of the Patient Health Questionnaire; PHQ-9) [41]; the short form of the workability index [42]; physical functioning in nursing tasks [35]; tiredness, sleepiness, and difficulties in recovering from work [43]; workinduced exertion in different body parts [44]; and psychosocial factors at work (Finnish work satisfaction questionnaire) [45] were investigated by questionnaires. FABs were measured with a questionnaire assessing FABs related to work (FAB-W) and physical activity (FAB-PA) [46]. Three questions considering long-term sick leave were removed from the original FABs questionnaire, because the participants were still in work [35].

Physical measurements included body mass index (BMI), movement control of the low back [47, 48], and performance tests for physical fitness, namely aerobic 


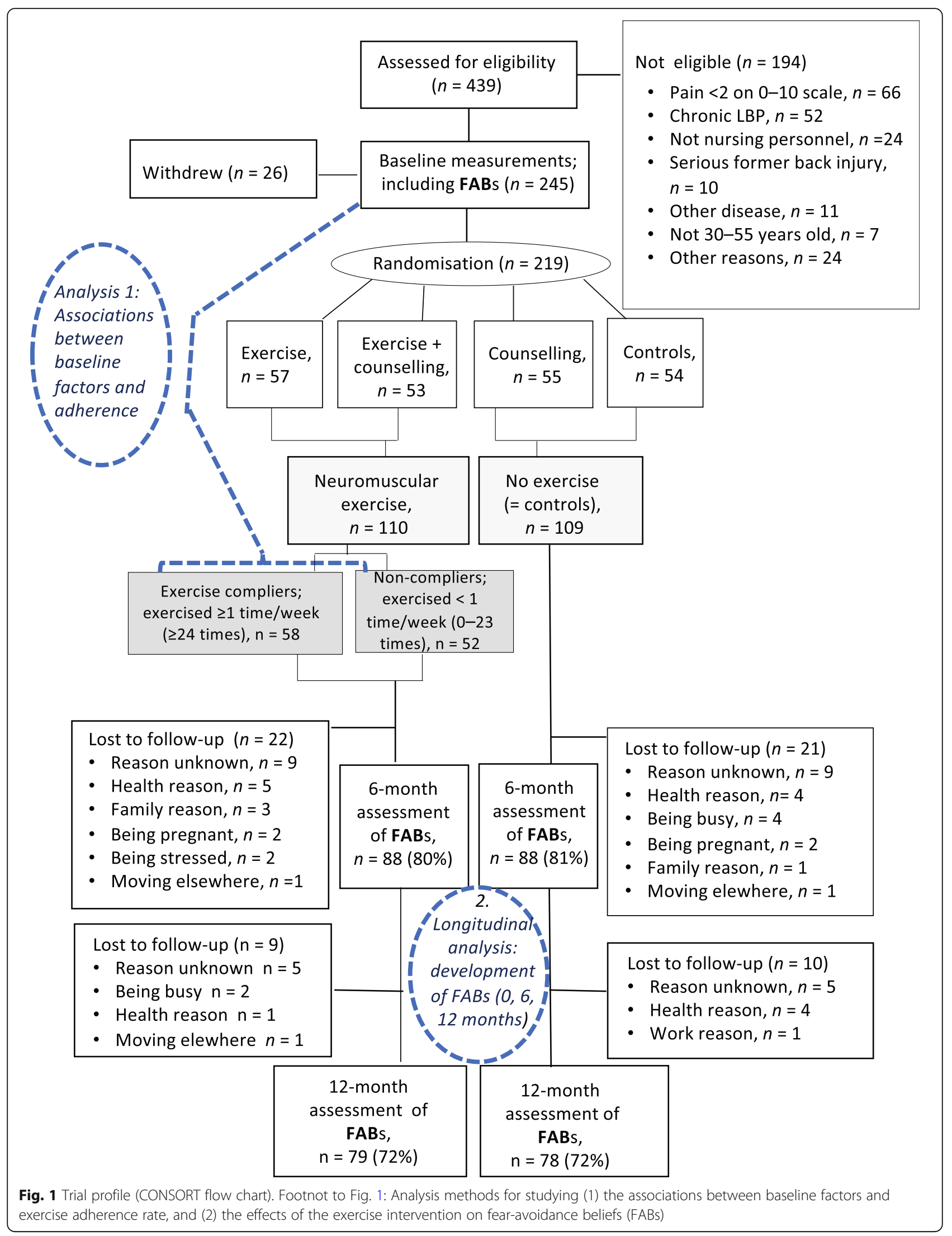


fitness by the 6-min walk test [49], muscular strength (modified push-up [50], one-legged squat with progressively increasing external load (10\% of body weight after each performance up to 40\%) [50], vertical jump [50], modified sit-ups [51]), agility by running a figure-ofeight [52], flexibility by trunk lateral side bending [50], and rhythm coordination [52]. More precise information on the measurements is given in the study protocol article [35], the article on the repeatability of the physical measurements [48], and the baseline analysis of the study sample [7].

\section{Exercise interventions in the NURSE-RCT}

The contents of the 6-month exercise intervention have been described previously [34]. The modified 6-month Pilates-type exercise intervention programme, which focused on controlling the neutral spine posture, started with light and easier exercises, and it was progressive in terms of demands for coordination, balance, and muscular strength over three stages. The goal was to exercise twice a week; during the first 2 months (stage I) in supervised neuromuscular exercise (NME) classes (lasting $60 \mathrm{~min}$ ) and during the next 4 months (stages II and III) in one supervised class and one home session with the help of a DVD (lasting $50 \mathrm{~min}$ ) or booklet produced for the study [34]. During stages II and III, the participants were also allowed to exercise in supervised group sessions more than once a week if exercise at home was inconvenient, and also only at home if the group sessions were difficult to attend. During the progression (stages II and III), the participants were allowed and/or advised to do easier exercises from the previous stage if the more challenging exercises proved too demanding.

The leaders of the neuromuscular exercise groups were all certified Pilates instructors with a background in physiotherapy, a master's degree in health sciences, or both [34]. Supervised exercise groups were organised in facilities near the workplaces of the healthcare personnel. Group sessions were provided on weekdays starting $15 \mathrm{~min}$ after the typical work shifts ended. The exercise classes, videos, and booklets were free for the participants, but they exercised in their own time [36].

\section{Adherence to exercise}

The instructors monitored the participation of supervised group exercise, and study subjects kept an exercise diary of their home practice. The structured exercise diaries were returned at the end of stage II (week 16) and stage III (week 24). Attendance of the supervised exercise sessions and the number of home exercise sessions were added together to determine the total exercise attendance rate.

\section{Motivational strategies}

All participants in the exercise group received an information letter at the beginning of the exercise intervention about the goals and principles of the exercise programme. During the 4th week of the first-stage exercise period, those who had not participated in any group-based exercise sessions received a telephone call from a research nurse (not involved in the exercise intervention or measurements), who encouraged them to start to exercise. All participants received two material packages (between stages I and II, and between stages II and III), which included an exercise DVD, exercise booklet, exercise diary for home practice, and a letter including information about the study and the importance of regular exercise. They also received two e-mails during stage II in order to encourage exercise, and a letter before the 6-month follow-up measurements from the principal investigator (JS).

To avoid any contamination to the back care counselling intervention (in the original four-arm setting), and to ensure exactly the same information to all who were allocated to the exercise group, the exercise instructors focused on instructing the standardised exercise programme (individual modifications due to musculoskeletal problems other than LBP were allowed). All other kinds of counselling (e.g. lifestyle, pain management, and ergonomics) were avoided in the exercise classes.

\section{Statistical methods}

Power calculations (at least 160 subjects needed) for the original NURSE-RCT have been reported previously [35], as has the randomisation of the participants [36].

Partial correlation analysis was conducted between all background and baseline variables and the adherence rate to determine which of the 60 different variables could have an association with the exercise adherence. Those variables showing a statistically significant association with the exercise adherence rate were selected for bivariate analysis with the adherence rate; the analytical methods were Spearman's correlation for continuous variables and the Kruskall-Wallis test for the categorical variables.

The median (24 times) was used to split the exercise group into the compliers (those who exercised once a week or more; $\geq 24$ times during the 24 weeks) and noncompliers (those who exercised 0-23 times) We examined the baseline characteristics of the participants randomised to the exercisers by the adherence status for those variables showing statistically significant associations with the adherence rate in the bivariate analysis. The analytical methods were the independent samples $t$ test, the $X^{2}$ test, or the Mann-Whitney $U$ test as applicable. 
To analyse the effects of the exercise programme on FABs, the mean differences in time (at three measurement points: baseline, 6 months, and 12 months) between the two groups (exercisers vs non-exercisers) were tested using a generalised linear mixed model (GLMM) (Fig. 1). To take the interaction between back counselling and exercise into consideration, all analyses were first adjusted for counselling. Second, the substudy was included as a random effect in all the GLLM analysis models to indicate the possible heterogeneity between the study sites and study time in the three consecutive sub-studies. Other confounding factors were background variables (age, civil status, education), workrelated factors (shift work/regular work, psycho-social factors at work [45], perceived work-induced lumbar exertion [44]), and health-related factors (BMI, hormonal status, perceived health, perceived fitness, blood pressure, current medication, self-reported physical activity and fitness components). Only those confounding factors that improved the model in the second stage in the sense of Bayesian information criteria were included in the final adjusted model.

After analysis according to the intention-to-treat (ITT) principle (Fig. 1), the study sample was assigned into two groups in order to investigate the effectiveness of the exercise on FABs, based on a per-protocol (PP) analysis. The mean difference in time $(0,6,12$ months) of exercise compliers ( $\geq 24$ exercise sessions) were estimated and compared to the results of a combined group of non-compliers and non-exercisers $(0-23$ exercise sessions + controls).

The correlation between the change in LBP intensity from the baseline to 6 months [34] and the change in the results of the FAB measurements after the intervention period were calculated by Spearman's correlation coefficient $\left(r_{\mathrm{s}}\right)$. Associations between professional status and fear avoidance at the baseline were analysed by analysis of variance (ANOVA).

All the analyses were conducted using SPSS (IBM Corp. Released 2017. IBM SPSS Statistics for Windows, Version 25.0 Armonk, NY: IBM Corp.).

\section{Results}

\section{Exercise adherence}

The target was for the participants to exercise twice a week - i.e. 48 sessions over 24 weeks. The mean attendance rate was $26.3(12.2)$ exercise sessions. Some $53 \%$ of the participants exercised 1-2 times/week. The mean attendance rate was 1.1 times/week during the whole intervention. During the last 8 weeks, the mean attendance rate of the group-based exercise decreased, but the home-based exercise rate increased (total amount remaining 1.1 times /week). Only two people out of the
110 exercised regularly twice a week during the 6-month intervention period.

Of those who were allocated to the exercise group, $10 \%$ did not exercise at all, and another $10 \%$ took part in only 1-5 exercise sessions in the 6-month period. Of the whole study sample $(n=219), 80 \%(n=176)$ and $72 \%$ $(n=157)$ participated in the 6-month and 12-month follow-up measurements, respectively [36]. At 6 months, 22 persons had dropped out, and $91 \%$ of them $(n=20)$ belonged to the least exercised group $(0-5$ exercise sessions). At 6 months, the dropout rate $(n=21)$ was equal among non-exercisers (Fig.1).

\section{Baseline variables associated with exercise adherence}

The bivariate associations between exercise attendance rates and continuous background and baseline variables is presented in Table 1. The associations for categorical variables are shown in Table 2. Between-group differences for those variables that had statistically significant correlations with adherence rates in the bivariate analysis are presented in Table 3 for the exercise compliers vs non-compliers.

Exercise non-compliers more often had a lower education level $(p=0.03)$ and did shift work $(p=0.02)$ compared to the exercise compliers (Table 3 ). From the baseline variables, higher fitness results in the onelegged squat $(p=0.043)$ and 6 -min walk test $(p=0.048)$ were detected for exercise compliers (Table 3 ).

Table 1 Bivariate correlation between baseline continuing variables and exercise adherence rate

\begin{tabular}{llll}
\hline & $\begin{array}{l}\text { Correlation with } \\
\text { adherence }\left(r_{\mathrm{s}}\right)\end{array}$ & Missing & p-value \\
\hline Running figure-of-eight & -0.27 & 9 & 0.006 \\
One-legged squat & 0.19 & 2 & 0.048 \\
6MWT & 0.28 & & 0.003 \\
Quality of life & & 4 & \\
$\quad$ Physical functioning & 0.19 & 4 & 0.045 \\
$\quad$ Energy & 0.15 & 4 & 0.12 \\
$\quad$ Social functioning & 0.18 & 4 & 0.06 \\
$\quad$ General health & 0.23 & & 0.019 \\
Workability index & 0.26 & 1 & 0.006 \\
Depression; PHQ-9 & -0.20 & 2 & 0.038 \\
Musculoskeletal exertion & 0.25 & 7 & 0.009 \\
FABs (total) & -0.26 & 1 & 0.009 \\
FAB-PA & -0.32 & 2 & 0.54 \\
Intensity of LBP & -0.06 &
\end{tabular}

$6 \mathrm{MWT}=6$-min walk test, $F A B$ fear-avoidance beliefs, $F A B-P A$ fear-avoidance beliefs related to physical activity, $L B P$ low back pain, $P H Q-9$ Patient Health Questionnaire, 9 items 
Table 2 Association between baseline categorical variables and exercise adherence rate, analysed by the Kruskall-Wallis test

\begin{tabular}{|c|c|c|c|c|c|}
\hline & $n$ & $\begin{array}{l}\text { Exercise adherence; } \\
\text { median }\end{array}$ & $\begin{array}{l}\text { Range of adherence; } \\
\text { min, max }\end{array}$ & Missing & $p$-value \\
\hline Education level & & & & 1 & 0.040 \\
\hline low (secondary school or less) & 30 & 18 & 0,40 & & \\
\hline medium (high school) & 74 & 28.5 & 0,55 & & \\
\hline high (university) & 5 & 16 & 0,29 & & \\
\hline Work type & & & & & 0.001 \\
\hline regular daytime work & 30 & 31.5 & 5,55 & & \\
\hline shift work & 72 & 21.4 & 0,44 & & \\
\hline other working time & 8 & 33 & 2,43 & & \\
\hline Occupation & & & & & 0.003 \\
\hline assistant nurse & 43 & 16 & 0,41 & & \\
\hline nurse & 56 & 28 & 0,55 & & \\
\hline other (radiographer, PT, midwife) & 11 & 35 & 4,50 & & \\
\hline Sub-study & & & & & 0.012 \\
\hline Nurse I & 27 & 12 & 0,39 & & \\
\hline Nurse II & 41 & 24 & 0,50 & & \\
\hline Nurse III & 42 & 29 & 0,55 & & \\
\hline Perceived health in comparison to others of the same age and gender & & & & & 0.037 \\
\hline moderate & 45 & 22 & 0,55 & & \\
\hline good or very good & 65 & 28 & 0,50 & & \\
\hline Perceived fitness in comparison to others of the same age and gender & & & & & 0.06 \\
\hline worse & 32 & 23 & 0,55 & & \\
\hline equal & 52 & 22 & 0,44 & & \\
\hline better & 26 & 31 & 0,55 & & \\
\hline Frequency of LBP & & & & 8 & 0.051 \\
\hline on some days of the week & 46 & 22 & 0,43 & & \\
\hline on most days & 38 & 29 & 0,55 & & \\
\hline daily & 18 & 40 & 0,42 & & \\
\hline
\end{tabular}

LBP low back pain, PT physiotherapist

\section{Fear-avoidance beliefs}

At the baseline, there was a difference in the levels of FABs between occupational groups in the whole study sample $(n=219)$. Nursing assistants had more FABs related to physical activity (FAB-PA, mean 15.5, SD 6.0, $n=89)$ than nurses $(12.0$, SD $5.9, n=102)$ and other professionals (11.6, SD 6.8, $n=28)(\mathrm{F}=9.5, p<0.001)$.

Exercise compliers showed lower values for FAB-PA at the baseline compared to non-compliers $(p=0.02$, Table $3)$. During the exercise intervention, both FAB-PA ( $p=$ 0.028 , adjusted for perceived occupational physical loading) and also FAB-W ( $p=0.007$, adjusted for age, shift work, perceived health, fitness and occupational physical loading, and push-ups) decreased in the exercise group compared to the non-exercisers (Fig. 2; ITT analysis). There was a dose-response; both FAB-PA $(p=0.006)$ and FAB-W $(p=0.016)$ decreased more in the high exercise adherence group compared to the less exercised and non-exercisers (Fig. 2; PP analysis). At 12 months follow-up, there were no more group differences in FAB-PA. A reduction in FAB-PA (from the baseline to 6 months) did not correlate with a reduction in LBP intensity $\left(r_{p}=0.03, p=0.54\right)$, but there was a correlation between a reduction in FAB-W and a reduction in LBP intensity $\left(r_{\mathrm{s}}=0.16, p=0.05\right)$.

\section{Discussion}

In this 6-month modified, Pilates-type exercise study for female healthcare personnel with sub-acute or recurrent, non-specific LBP, those possessing a lower basic education level, working shifts, and having lower levels of fitness and higher levels of physical activity-related FABs at the baseline had a lower exercise adherence. Exercising during the intervention reduced levels of FAB-PA and FAB-W, and there was a dose-response: the levels of 
Table 3 Baseline variables of the participants (randomised to the exercise group) by exercise adherence status

\begin{tabular}{|c|c|c|c|c|c|c|c|c|}
\hline & \multicolumn{3}{|c|}{$\begin{array}{l}\text { Compliers ( } \geq 24 \text { exercise } \\
\text { sessions), } n=58\end{array}$} & \multicolumn{3}{|c|}{$\begin{array}{l}\text { Non-compliers ( } 0-23 \text { exercise } \\
\text { sessions), } n=52\end{array}$} & \multirow[t]{2}{*}{ Miss-ing } & \multirow[t]{2}{*}{$p$-value } \\
\hline & Mean (SD) & $n$ & $\%$ & Mean (SD) & $n$ & $\%$ & & \\
\hline Running figure-of-eight; seconds & $7.7(1.0)$ & & & $8.0(1.2)$ & & & 9 & 0.20 \\
\hline One-legged squat; (0-12 reps) & $9.9(2.3)$ & & & $8.9(2.9)$ & & & 2 & 0.043 \\
\hline 6MWT; metres & $623.0(43.8)$ & & & $603.4(56.2)$ & & & - & 0.048 \\
\hline \multicolumn{9}{|l|}{ Quality of life } \\
\hline Physical functioning (0-100) & $87.3(11.1)$ & & & $83.4(13.4)$ & & & 4 & 0.17 \\
\hline General health $(0-100) *$ & $70.2(16.4)$ & & & $64.5(17.5)$ & & & 4 & 0.08 \\
\hline Workability index (3-27) & $22.2(2.6)$ & & & $21.9(2.9)$ & & & & 0.20 \\
\hline PHQ-9 (0-27) & $7.4(4.5)$ & & & $8.5(5.3)$ & & & 1 & 0.29 \\
\hline Musculoskeletal exertion (7-35) * & $12.2(3.8)$ & & & $13.5(4.0)$ & & & 2 & 0.10 \\
\hline FABs total (0-78) & $23.2(12.9)$ & & & $27.3(14.5)$ & & & 7 & 0.07 \\
\hline FAB-PA; (0-30) & $12.6(6.9)$ & & & $15.4(6.4)$ & & & 1 & 0.019 \\
\hline LBP intensity; (VAS 0-100) & $36.9(19.9)$ & & & $35.9(19.9)$ & & & 1 & 0.79 \\
\hline Education level & & & & & & & - & 0.026 \\
\hline low (secondary school or less) & & 14 & 24.1 & & 23 & 44.2 & & \\
\hline medium or high & & 44 & 75.9 & & 29 & 55.8 & & \\
\hline Work type & & & & & & & - & 0.023 \\
\hline regular work & & 24 & 41.4 & & 11 & 21.2 & & \\
\hline shift work & & 34 & 58.6 & & 41 & 78.8 & & \\
\hline Profession & & & & & & & - & 0.052 \\
\hline assistant nurse & & 18 & 31.0 & & 25 & 48.1 & & \\
\hline nurse & & 31 & 53.4 & & 25 & 48.1 & & \\
\hline other (radiographer, PT, midwife) & & 9 & 15.5 & & 2 & 3.8 & & \\
\hline Sub-study & & & & & & & - & 0.042 \\
\hline Sub-study I & & 9 & 15.5 & & 18 & 34.6 & & \\
\hline Sub-study II & & 22 & 37.9 & & 19 & 36.5 & & \\
\hline Sub-study III & & 27 & 46.6 & & 15 & 28.8 & & \\
\hline $\begin{array}{l}\text { Perceived health in comparison to others } \\
\text { of the same age and sex; }{ }^{\circ}\end{array}$ & & & & & & & - & 0.14 \\
\hline moderate & & 20 & 34.5 & & 25 & 48.1 & & \\
\hline good or very good & & 38 & 65.5 & & 27 & 51.8 & & \\
\hline Frequency of LBP; ${ }^{\circ}$ & & & & & & & 8 & 0.12 \\
\hline on some days of the week & & 21 & 38 & & 25 & 54 & & \\
\hline on most days & & 26 & 46 & & 12 & 26 & & \\
\hline daily & & 9 & 16 & & 9 & 20 & & \\
\hline
\end{tabular}

${ }^{*}$ normal distribution, independent samples $t$-test, Mann-Whitney $U$ test, ${ }^{\circ} X^{2}$ test. $F A B-P A$ physical activity-related fear-avoidance beliefs, $L B P$ low back pain, $P H Q-9$ Nine-item Patient Health Questionnaire measuring depression, PT physical therapist, VAS visual analogue scale of $0-100$ during the past 4 weeks

FAB-PA and FAB-W decreased more in more exercised persons.

In exercise interventions, levels of exercise adherence usually drop over time; approximately $50 \%$ reduction in 12 months has been presented $[26,53]$. In the present intervention, participation in the supervised groups decreased across time, but the amount of home-based exercise increased commensurately. The exercise videos, booklets, supportive e-mails and letters probably helped in maintaining the same exercise adherence level throughout the 6-month intervention. While we knew that exercise adherence is usually only modest at best among people with musculoskeletal pain [20], and that shift work makes attending regular group-based exercise demanding [54], the exercise adherence rate in the present study was lower than we expected. In 2012- 


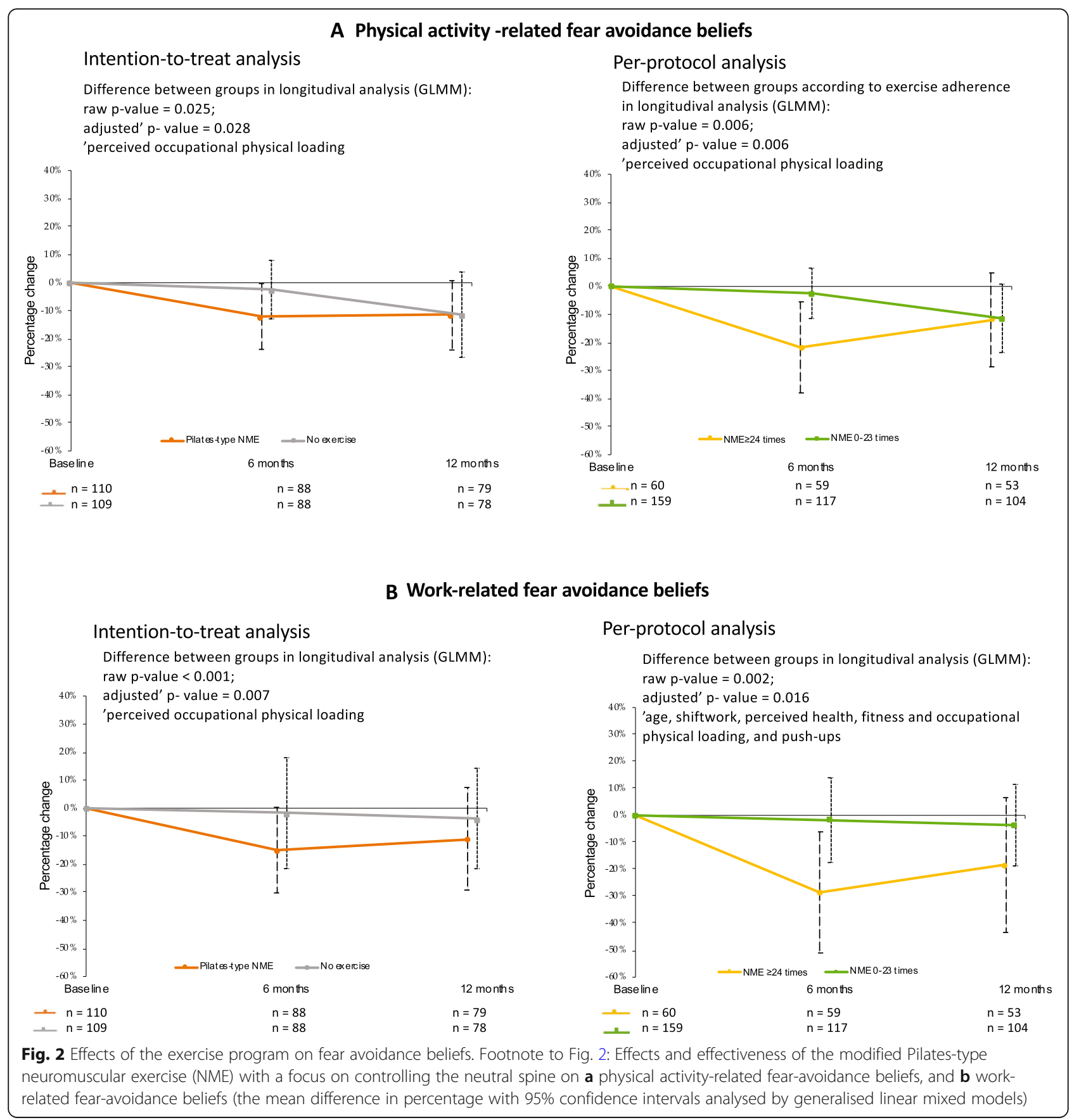

2014, when the study interventions were conducted, Pilates was quite a popular exercise type in Finland, and for that reason it was expected to be more attractive than a typically conventional/traditional neuromuscular exercise form.

It has been suggested that factors associated with exercise adherence among LBP patients can be divided into three categories [55]: 1) physical factors like pain [55] and perceived health status [56]; 2) psychological factors such as the fear of pain [23], diagnostic uncertainty [22], low self-efficacy [21], and depression and anxiety [21]; and 3) environmental factors, such as difficulty in integrating exercise into daily life [22, 55], lack of time [22, $23,55]$, and intervention-related variables [33]. This classification is partly insufficient: it is difficult to place education level, which is a socio-demographic background factor, into any of those categories. Socio-economic status is associated with back-related beliefs: those with high socio-economic status are more prone to believe that one should stay active regardless LBP [57]. 
Education level has been shown to affect adherence to exercise progression among people with chronic LBP [58], strength training [56], and leisure-time physical activity [59]. In the present study, lower basic education level was also associated with lower exercise adherence, even though healthcare workers are a fairly homogenous group, and socio-demographic differences are generally small in Finland [60].

In previous studies, LBP intensity [55] and older age [58] compromised adherence to exercise or exercise progression. Contradictory to earlier studies, they had no effect in the present study, perhaps because in most participants the intensity of LBP was mild to moderate, they were still working, and the age range was set to 3055 years. Higher physical fitness level at the baseline contributed to better exercise adherence. To our knowledge, association between baseline physical fitness and exercise adherence in later intervention has not been reported previously.

FABs-PA results at baseline in the current study were comparable to those detected among French hospital workers with recurrent LBP [61], but lower than among LBP patients seeking medical care for their pain [62]. FABs related to physical activity are known to affect exercise adherence [22]; activities or exercises are avoided for fear of increasing pain [23]. Cognitive and psychological interventions [27] and graded activity [63] are usually considered helpful in the management of fear avoidance-related pain. An intervention including education in addition to exercise was slightly more effective in reducing FABs-PA among French hospital workers with LBP than the present study [61]. Interventions to reduce FABs very seldom include exercise only, but a Pilatestype exercise has shown to reduce FABs more than stationary cycling in short term among chronic LBP patients [64]. We hypothesise that this modified, slowly progressing Pilates-type exercise programme, which was conducted at the pace of the participant's calm breathing tempo, might have given the participants positive experiences of movement. They could move in a way that they could control; the movements were not harmful or dangerous and could even release pain. This might explain the reduction of $F A B$ levels during the exercise intervention.

Moderators (or treatment effect modifiers) are baseline characteristics that influence the outcome of treatment [65]. Mediators are factors that change during or as a consequence of an intervention and thereby influence outcome [65]. Thus, it might be hypothesised that the earlier reported reduction of LBP intensity among the present study sample after exercise intervention [34] might have been mediated by a reduction in the fear of movement. Nevertheless, there was no correlation between the reduction of LBP intensity and the reduction of FAB-PA, but exercise adherence was the key factor.
Those with a lower FAB-PA at the baseline exercised more, and those who exercised more gained more positive results in pain reduction [34]. While we measured pain intensity only at the baseline and after the 6-month exercise intervention - i.e. not during the intervention period - we cannot say anything about causality. Exercising more might have reduced the pain levels due to exercise-induced hypoalgesia [66-68], or a potential rapid reduction of pain intensity at the beginning of the exercise intervention might have decreased the levels of FAB-PA, and thus increased the motivation to exercise. In exercise intervention, both FABs [69] and exercise adherence [26] can mediate the outcome, i.e. LBP intensity. Identification of the mechanisms through which different treatments affect outcomes is complicated, and there is a clear need for further research that investigates plausible mediators [69].

The reduction of FABs during the intervention was statistically significant, but we do not know its clinical relevance (three questions related to returning to work were removed from the original FAB Questionnaire). Among hospital workers with recurrent LBP, an intervention combining education and exercise reduced FABs-PA, but did not reduce LBP recurrence episodes in two-year follow up [61]. For those healthcare workers with previous LBP, both the physical workload and FABs are important in the development of new episodes of LBP [70].

A lack of time is the most frequently reported barrier to leisure-time physical activity or exercise, both among the general population [31, 71] and among people with LBP [23]. Those working shifts had a lower exercise adherence than those working at regular times. Among nursing personnel, shift work is also associated with sleeping problems, fatigue, and lack of energy [72, 73], which might compromise exercise adherence.

Increasing adherence to exercise is an important factor for the longer-term effectiveness of an intervention. Integrating educational components to exercise sessions, like strategic planning [23], self-monitoring [56], goal-setting $[25,74]$, supplementary printed material, motivation strategies and positive re-enforcement [74], encouragement and action planning to overcome barriers to exercise [23] have been suggested to increase exercise adherence. Also leadership and organisation skills [21], favourable environment and pleasure associated with exercise [23], and appropriate intensity of the training content [75] might help in reducing fear of pain and pain itself [23] and thus increase exercise adherence. Identification of especially those who have a low education level, and targeting motivating efforts at them [56] might be effective.

Understanding the causality and reasons for exercise adherence is complicated, multidimensional, and difficult to 
study. People do not always behave in the way they intend to behave. Motivation alone is not sufficient to trigger an action, and one is often confronted with obstacles [23]. In the present study, exercise adherence was lower among those with a lower level of basic education. The levels of baseline FABs were also higher among assistant nurses. In clinical practice, motivational strategies with a focus on decreasing FABs especially among people with a low education level could be beneficial. Unfortunately, there is a lack of measurement methods to identify those who would benefit most from motivational actions.

\section{Limitations}

This study was a secondary analysis of the NURSE-RCT. Investigating associations between individual factors at the baseline and exercise adherence was not planned simultaneously with planning the RCT, and it was not written into the study protocol [35]. We arrived at the idea for the study after we detected the dose response of exercising on LBP intensity and movement control impairments [34]. Due to the four-arm setting of the original NURSE-RCT (combined exercise + counselling, exercise only, counselling only, controls), targeting motivational strategies at exercisers (exercise only and the combined group) would have been difficult without contaminating the back care counselling intervention.

Several additional measurements might have been beneficial: the immediate effects of the exercise sessions (to pain or other bodily sensations), home environment, previous physical activity (in earlier years), and the number and ages of the participants' children were not ascertained in the study. This might have broadened our understanding of the factors affecting exercise adherence. We measured only the number of exercise sessions, which were either supervisor-documented (for group sessions) or self-reported (for home practice). The research calls for standard validated measures of exercise adherence [20].

\section{Conclusion}

Participants with lower education and fitness levels who worked shifts and had high physical activity-related fearavoidance beliefs at the baseline had a lower adherence to the 6-month neuromuscular exercise programme. Exercising with good adherence reduced levels of FABs, which are known to be linked with prolonged LBP. In exercise interventions, motivational strategies should be targeted at those with low education and fitness levels and high fear-avoidance beliefs to achieve better exercise adherence. In exercise intervention studies, strategies to enhance and/or maintain exercise adherence need to be taken more seriously, because adherence is a key link between intervention and outcomes.

\begin{abstract}
Abbreviations
ANOVA: Analysis of variance; BMl: Body mass index; DVD: Digital video disc; FABs: Fear-avoidance beliefs; FAB-PA: Fear-avoidance beliefs related to physical activity; FAB-W: Work-related fear-avoidance beliefs;

GLMM: Generalised linear mixed model; ITT: Intention to treat; LBP: Low back pain; NME: Neuromuscular exercise; NRS: Numeric rating scale; 0-10; PHQ9: Patient health questionnaire, 9 items; PP: Per protocol; RCT: Randomised controlled trial; SD: Standard deviation; VAS: Visual analogue scale; 0-100
\end{abstract}

\section{Acknowledgements}

The authors wish to thank the nursing personnel who participated in the NURSE-RCT, the instructors who supervised the exercise groups, and the personnel who conducted the measurements at the UKK Institute for Health Promotion Research. They also wish to thank the head nurses and other personnel of Social and Health Services at the City of Tampere and Tampere University of Applied Sciences for organising locations for exercising close to the workplaces.

\section{Authors' contributions}

All authors have read and approved the final manuscript. AT is the corresponding author, and she drafted the manuscript. She planned the exercise intervention, trained the other exercise instructors, produced the exercise videos and booklets, and supervised some of the exercise groups. She conducted the literature search and the bivariate statistical analysis. MK contributed to the design of the present study and the interpretation and presentation of the results. MR contributed to the interpretation and presentation of the results. KT verified the bivariate statistical analysis, and he conducted all the multivariate analyses. He also contributed to the presentation of the results of the statistical analysis. JP is the responsible medical doctor of the study. He contributed to the design of the study and the interpretation and presentation of the results. JS is the principal researcher of the NURSE-RCT. She is responsible for measurement selection and development, and for data collection and management. She contributed to the design of the study and the interpretation and presentation of the results of the present study.

\section{Funding}

The original NURSE RCT received funding from the Social Insurance Institution of Finland (37/26/2011 and 31/26/2015) for planning and conducting the study interventions and collecting the data, and from Tampere University Hospital (9R015, 9S017, 9 T015, 9 U017, 9 V014, and 9X013) for the data analysis and reporting. Hence, the current study, which is a secondary analysis of the NURSE RCT, received funding from Tampere University Hospital.

\section{Availability of data and materials}

The datasets used and analysed during the current study are available from the principal researcher (JS; jaana.suni@ukkinstituutti.fi) of the NURSE RCT and from tommi.vasankari@ukkinstituutti.fi upon reasonable request.

\section{Ethics approval and consent to participate}

The participants gave their informed consent in written form at their first visit to the research centre (i.e. at the baseline measurement of the study), and the trial was conducted according to the Declaration of Helsinki. The study was approved by the Ethics Committee of Pirkanmaa Hospital District, Finland (ETL code R08157).

\section{Consent for publication}

Not applicable.

\section{Competing interests}

The authors declare that they have no competing interests.

\section{Author details}

${ }^{1}$ UKK Institute for Health Promotion Research, Tampere, Finland. ${ }^{2}$ Department of Physical and Rehabilitation Medicine, Tampere University Hospital, Tampere, Finland. 
Received: 9 September 2019 Accepted: 20 April 2020 Published online: 04 May 2020

\section{References}

1. Hartvigsen J, Hancock MJ, Kongsted A, Louw Q, Ferreira ML, Genevay S, Hoy D, Karppinen J, Pransky G, Sieper J, et al. What low back pain is and why we need to pay attention. Lancet. 2018;391(10137):2356-67.

2. Yassi A, Lockhart K. Work-relatedness of low back pain in nursing personnel: a systematic review. Int J Occup Environ Health. 2013;19(3):223-44.

3. Chen MJ, Weng SS. Psychological symptoms among hospital nurses in Taiwan: a cross sectional study. BMC Womens Health. 2017;17(1):101.

4. Jensen JN, Holtermann A, Clausen T, Mortensen OS, Carneiro IG, Andersen $\mathrm{LL}$. The greatest risk for low-back pain among newly educated female health care workers; body weight or physical work load? BMC Musculoskelet Disord. 2012;13:87.

5. Lagerstrom M, Hansson T, Hagberg M. Work-related low-back problems in nursing. Scand J Work Environ Health. 1998;24(6):449-64.

6. Frost DM, Beach TA, Callaghan JP, McGill SM. Exercise-based performance enhancement and injury prevention for firefighters: contrasting the fitnessand movement-related adaptations to two training methodologies. J Strength Conditioning Res. 2015;29(9):2441-59.

7. Taulaniemi A, Kuusinen L, Tokola K, Kankaanpaa M, Suni JH. Bio-psychosocial factors are associated with pain intensity, physical functioning, and ability to work in female healthcare personnel with recurrent low back pain. J Rehabil Med. 2017;49:667-76.

8. Kolu P, Tokola K, Kankaanpaa M, Suni J. Evaluation of the effects of physical activity, cardiorespiratory condition, and neuromuscular fitness on direct healthcare costs and sickness-related absence among nursing personnel with recurrent nonspecific low Back pain. Spine (Phila Pa 1976). 2017;42(11): 854-62.

9. Rasmussen CD, Jorgensen MB, Clausen T, Andersen LL, Stroyer J, Holtermann A. Does self-assessed physical capacity predict development of low back pain among health care workers? A 2-year follow-up study. Spine (Phila Pa 1976). 2013;38(3):272-6.

10. Babiolakis CS, Kuk JL, Drake JD. Differences in lumbopelvic control and occupational behaviours in female nurses with and without a recent history of low back pain due to back injury. Ergonomics. 2015;58(2):235-45.

11. Suni JH, Taanila H, Mattila VM, Ohrankammen O, Vuorinen P, Pihlajamaki H, Parkkari J. Neuromuscular exercise and counseling decrease absenteeism due to low back pain in young conscripts: a randomized, population-based primary prevention study. Spine (Phila Pa 1976). 2013;38(5):375-84.

12. Luomajoki HA, Bonet Beltran MB, Careddu S, Bauer CM. Effectiveness of movement control exercise on patients with non-specific low back pain and movement control impairment: a systematic review and meta-analysis. Musculoskelet Sci Pract. 2018;36:1-11.

13. Van Hoof W, O'Sullivan K, O'Keeffe M, Verschueren S, O'Sullivan P, Dankaerts $W$. The efficacy of interventions for low back pain in nurses: a systematic review. Int J Nurs Stud. 2018;77:222-31.

14. Bousema EJ, Verbunt JA, Seelen HA, Vlaeyen JW, Knottnerus JA. Disuse and physical deconditioning in the first year after the onset of back pain. Pain. 2007;130(3):279-86.

15. Choi BK, Verbeek JH, Tam WW, Jiang JY. Exercises for prevention of recurrences of low-back pain. Cochrane Database Syst Rev. 2010;1: CD006555.

16. Balague F, Mannion AF, Pellise F, Cedraschi C. Non-specific low back pain. Lancet. 2012;379(9814):482-91.

17. Steffens D, Maher CG, Pereira LS, Stevens ML, Oliveira VC, Chapple M, Teixeira-Salmela LF, Hancock MJ. Prevention of low Back pain: a systematic review and meta-analysis. JAMA Intern Med. 2016;176(2):199-208.

18. Shiri R, Falah-Hassani K. Does leisure time physical activity protect against low back pain? Systematic review and meta-analysis of 36 prospective cohort studies. Br J Sports Med. 2017;51(19):1410-8.

19. Falla D, Hodges PW. Individualized exercise interventions for spinal pain. Exerc Sport Sci Rev. 2017;45(2):105-15.

20. Jordan JL, Holden MA, Mason EE, Foster NE. Interventions to improve adherence to exercise for chronic musculoskeletal pain in adults. Cochrane Database Syst Rev. 2010;1:CD005956.

21. Jack K, McLean SM, Moffett JK, Gardiner E. Barriers to treatment adherence in physiotherapy outpatient clinics: a systematic review. Man Ther. 2010; 15(3):220-8.
22. Slade SC, Patel S, Underwood M, Keating JL. What are patient beliefs and perceptions about exercise for nonspecific chronic low Back pain? A systematic review of qualitative studies. Clin J Pain. 2014;30(11):995-1005.

23. Mathy C, Cedraschi C, Broonen JP, Azzi A, Henrotin Y. Volition and low back pain: when patients talk. Ann Phys Rehabil Med. 2015;58(6):326-31.

24. Escolar-Reina PM-MF, Gascón-Cánovas JJ, Montilla-Herrador J, JimenoSerrano FJ, de Oliveira Sousa SL, del Baño-Aledo ME, Lomas-Vega R. How do care-provider and home exercise program characteristics affect patient adherence in chronic neck and back pain: a qualitative study. BMC Health Serv Res. 2010;10(60).

25. Nicolson PJA, Bennell KL, Dobson FL, Van Ginckel A, Holden MA, Hinman RS. Interventions to increase adherence to therapeutic exercise in older adults with low back pain and/or hip/knee osteoarthritis: a systematic review and meta-analysis. Br J Sports Med. 2017;51(10):791-9.

26. Van Dillen LR, Norton BJ, Sahrmann SA, Evanoff BA, Harris-Hayes M, Holtzman GW, Earley J, Chou I, Strube MJ. Efficacy of classification-specific treatment and adherence on outcomes in people with chronic low back pain. A one-year follow-up, prospective, randomized, controlled clinical trial. Man Ther. 2016;24:52-64.

27. Linton SJ, Shaw WS. Impact of psychological factors in the experience of pain. Phys Ther. 2011;91(5):700-11.

28. Wertli MM, Rasmussen-Barr E, Weiser S, Bachmann LM, Brunner F. The role of fear avoidance beliefs as a prognostic factor for outcome in patients with nonspecific low back pain: a systematic review. Spine J. 2014;14(5):816-36 e814.

29. Baez S, Hoch MC, Hoch JM. Evaluation of cognitive behavioral interventions and Psychoeducation implemented by rehabilitation specialists to treat fearavoidance beliefs in patients with low Back pain: a systematic review. Arch Phys Med Rehabil. 2018;99(11):2287-98.

30. Kjaer P, Kongsted A, Ris I, Abbott A, Rasmussen CDN, Roos EM, Skou ST, Andersen TE, Hartvigsen J. GLA:D((R)) Back group-based patient education integrated with exercises to support self-management of back pain development, theories and scientific evidence. BMC Musculoskelet Disord. 2018;19(1):418.

31. Carraca EV, Mackenbach JD, Lakerveld J, Rutter H, Oppert JM, De Bourdeaudhuij I, Compernolle S, Roda C, Bardos H, Teixeira PJ. Lack of interest in physical activity - individual and environmental attributes in adults across Europe: the SPOTLIGHT project. Prev Med. 2018;111:41-8.

32. Costa Lda C, Maher CG, McAuley JH, Hancock MJ, Smeets RJ. Self-efficacy is more important than fear of movement in mediating the relationship between pain and disability in chronic low back pain. Eur J Pain. 2011;15(2): 213-9.

33. Beinart NA, Goodchild CE, Weinman JA, Ayis S, Godfrey EL. Individual and intervention-related factors associated with adherence to home exercise in chronic low back pain: a systematic review. Spine J. 2013;13(12):1940-50.

34. Taulaniemi A, Kankaanpää M, Tokola K, Parkkari J, Suni JH. Neuromuscular exercise reduces low back pain intensity and improves physical functioning in nursing duties among female healthcare workers; secondary analysis of a randomised controlled trial. BMC Musculoskelet Disord. 2019;20(1):328.

35. Suni JH, Rinne M, Kankaanpaa M, Taulaniemi A, Lusa S, Lindholm H, Parkkari J. Neuromuscular exercise and back counselling for female nursing personnel with recurrent non-specific low back pain: study protocol of a randomised controlled trial (NURSE-RCT). BMJ Open Sport Exerc Med. 2016: 2(1):e000098.

36. Suni JH, Kolu P, Tokola K, Raitanen J, Rinne M, Taulaniemi A, Parkkari J, Kankaanpaa M. Effectiveness and cost-effectiveness of neuromuscular exercise and back care counseling in female healthcare workers with recurrent non-specific low back pain: a blinded four-arm randomized controlled trial. BMC Public Health. 2018;18(1):1376.

37. Dionne CE, Dunn KM, Croft PR, Nachemson AL, Buchbinder R, Walker BF, Wyatt M, Cassidy JD, Rossignol M, Leboeuf-Yde C, et al. A consensus approach toward the standardization of back pain definitions for use in prevalence studies. Spine (Phila Pa 1976). 2008;33(1):95-103.

38. Ostelo RW, Deyo RA, Stratford P, Waddell G, Croft P, Von Korff M, Bouter LM, de Vet HC. Interpreting change scores for pain and functional status in low back pain: towards international consensus regarding minimal important change. Spine (Phila Pa 1976). 2008;33(1):90-4.

39. Hays RD, Sherbourne CD, Mazel RM. The RAND 36-item health survey 1.0. Health Econ. 1993;2(3):217-27.

40. Aalto AM, Aro, AR., Teperi, J.: RAND-36 as a measure of Health-Related Quality of life. Reliability, construct validity and reference values in the 
Finnish general population. RAND-36 terveyteen liittyvän elämänlaadun mittarina. Mittarin luotettavuus ja suomalaiset väestöarvot. In. Helsinki: Stakes, Tutkimuksia 101; 1999.

41. Kroenke K, Spitzer RL, Williams JB. The PHQ-9: validity of a brief depression severity measure. J Gen Intern Med. 2001;16(9):606-13.

42. IImarinen J. Work ability--a comprehensive concept for occupational health research and prevention. Scand J Work Environ Health. 2009;35(1):1-5.

43. Karhula K, Harma M, Sallinen M, Hublin C, Virkkala J, Kivimaki M, Vahtera J, Puttonen S. Association of job strain with working hours, shift-dependent perceived workload, sleepiness and recovery. Ergonomics. 2013;56(11):1640-51.

44. Ketola R, Toivonen R, Häkkänen M, Luukkonen R, Takala E-P, Viikari-Juntura E. Effects of ergonomic intervention in work with video display units. Scand J Work Environ Health. 2002;28(1):18-24.

45. Haukka E, Pehkonen I, Leino-Arjas P, Viikari-Juntura E, Takala EP, Malmivaara A, Hopsu L, Mutanen P, Ketola R, Virtanen T, et al. Effect of a participatory ergonomics intervention on psychosocial factors at work in a randomised controlled trial. Occup Environ Med. 2010;67(3):170-7.

46. Waddell G, Newton M, Henderson I, Somerville D, Main CJ. A fear-avoidance beliefs questionnaire ( $\mathrm{FABQ}$ ) and the role of fear-avoidance beliefs in chronic low back pain and disability. Pain. 1993;52(2):157-68.

47. Luomajoki H, Kool J, de Bruin ED, Airaksinen O. Reliability of movement control tests in the lumbar spine. BMC Musculoskelet Disord. 2007;8:90.

48. Taulaniemi RPA, Kankaanpaa MJ, Tokola KJ, Luomajoki HA, Suni JH. Reliability of musculoskeletal fitness tests and movement control impairment test battery in female health-care personnel with recurrent low back pain. J Nov Physiother. 2016;6(1):282.

49. Jenkins S, Cecins N, Camarri B, Williams C, Thompson P, Eastwood P. Regression equations to predict 6-minute walk distance in middle-aged and elderly adults. Physiother Theor Pract. 2009;25(7):516-22.

50. Suni JH, Oja P, Laukkanen RT, Milinnalo SI, Pasanen ME, Vuori IM, Vartiainen TM, Bos K. Health-related fitness test battery for adults: aspects of reliability. Arch Phys Med Rehabil. 1996;77(4):399-405.

51. Engström LM, Ekblom, B., Forsberg, A, Koch MV. \& Seger J. (in Swedish) Livsstil - Prestation - Hälsa. Motionsvanor, fysisk prestationsförmåga och hälsotillstånd bland svenska kvinnor och män I åldern 20-65 år., vol. 64. Ödeshög, Sverige: AB Danagård Grafiska; 1993.

52. Rinne MB, Pasanen ME, Miilunpalo SI, Oja P. Test-retest reproducibility and inter-rater reliability of a motor skill test battery for adults. Int I Sports Med. 2001;22(3):192-200.

53. Hakkinen A, Ylinen J, Kautiainen $\mathrm{H}$, Tarvainen U, Kiviranta I. Effects of home strength training and stretching versus stretching alone after lumbar disk surgery: a randomized study with a 1-year follow-up. Arch Phys Med Rehabil. 2005;86(5):865-70.

54. Flahr H, Brown WJ, Kolbe-Alexander TL. A systematic review of physical activity-based interventions in shift workers. Prev Med Rep. 2018;10:323-31.

55. Boutevillain L, Dupeyron A, Rouch C, Richard E, Coudeyre E. Facilitators and barriers to physical activity in people with chronic low back pain: a qualitative study. PLoS One. 2017;12(7):e0179826.

56. Rhodes RE, Lubans DR, Karunamuni N, Kennedy S, Plotnikoff R. Factors associated with participation in resistance training: a systematic review. $\mathrm{Br} J$ Sports Med. 2017;51(20):1466-72.

57. Suman A, Bostick GP, Schaafsma FG, Anema JR, Gross DP. Associations between measures of socio-economic status, beliefs about back pain, and exposure to a mass media campaign to improve back beliefs. BMC Public Health. 2017;17(1):504.

58. Franco KFM, Franco Y, Oliveira NTB, Padula RS, Cabral CMN. Predictive factors for progression through the difficulty levels of Pilates exercises in patients with low back pain: a secondary analysis of a randomized controlled trial. Braz J Phys Ther. 2018;22(6):512-8.

59. O'Donoghue G, Kennedy A, Puggina A, Aleksovska K, Buck C, Burns C, Cardon G, Carlin A, Ciarapica D, Colotto M, et al. Socio-economic determinants of physical activity across the life course: a "DEterminants of Dlet and physical ACtivity" (DEDIPAC) umbrella literature review. PLoS One. 2018;13(1):e0190737.

60. Blom R, Kankainen T, Melin H: Jakaantunut Suomi. Raportti ISSP 2009 Suomen aineistosta (in Finnish): international social survey program, report from Finnish data. In: Yhteiskuntatieteellisen tietoarkiston julkaisuja. 2012.

61. Chaleat-Valayer E, Denis A, Abelin-Genevois K, Zelmar A, Siani-Trebern F, Touzet S, Bergeret A, Colin C, Fassier JB. Long-term effectiveness of an educational and physical intervention for preventing low-back pain recurrence: a randomized controlled trial. Scand J Work Environ Health. 2016;42(6):510-9.

62. George SZ, Fritz JM, Childs JD. Investigation of elevated fear-avoidance beliefs for patients with low back pain: a secondary analysis involving patients enrolled in physical therapy clinical trials. J Orthop Sports Phys Ther. 2008;38(2):50-8.

63. Foster NE, Anema JR, Cherkin D, Chou R, Cohen SP, Gross DP, Ferreira PH, Fritz JM, Koes BW, Peul W, et al. Prevention and treatment of low back pain: evidence, challenges, and promising directions. Lancet. 2018;391(10137): 2368-83.

64. Marshall PW, Kennedy S, Brooks C, Lonsdale C. Pilates exercise or stationary cycling for chronic nonspecific low back pain: does it matter? A randomized controlled trial with 6-month follow-up. Spine (Phila Pa 1976). 2013;38(15): E952-9.

65. Nicholas MK, Linton SJ, Watson PJ, Main CJ. Decade of the flags working G: early identification and management of psychological risk factors ("yellow flags") in patients with low back pain: a reappraisal. Phys Ther. 2011;91(5): 737-53.

66. Sluka KA, Frey-Law L, Hoeger Bement M. Exercise-induced pain and analgesia? Underlying mechanisms and clinical translation. Pain. 2018; 159(Suppl 1):S91-7.

67. Mata Diz JB, de Souza JR, Leopoldino AA, Oliveira VC. Exercise, especially combined stretching and strengthening exercise, reduces myofascial pain: a systematic review. J Phys. 2017;63(1):17-22.

68. Black CD, Huber JK, Ellingson LD, Ade CJ, Taylor EL, Griffeth EM, Janzen NR, Sutterfield SL. Exercise-induced Hypoalgesia is not influenced by physical activity type and amount. Med Sci Sports Exerc. 2017;49(5):975-82.

69. Mansell G, Kamper SJ, Kent P. Why and how back pain interventions work: what can we do to find out? Best Pract Res Clin Rheumatol. 2013;27:685-97.

70. Jensen JN, Albertsen K, Borg V, Nabe-Nielsen K. The predictive effect of fearavoidance beliefs on low back pain among newly qualified health care workers with and without previous low back pain: a prospective cohort study. BMC Musculoskelet Disord. 2009;10:117.

71. Borodulin K, Sipila N, Rahkonen O, Leino-Arjas P, Kestila L, Jousilahti P, Prattala R. Socio-demographic and behavioral variation in barriers to leisuretime physical activity. Scand J Public health. 2016;44(1):62-9.

72. Books C, Coody LC, Kauffman R, Abraham S. Night shift work and its health effects on nurses. Health Care Manag. 2017;36(4):347-53.

73. Leyva-Vela B, Jesus Llorente-Cantarero F, Henarejos-Alarcon S, MartinezRodriguez A. Psychosocial and physiological risks of shift work in nurses: a cross-sectional study. Cent Eur J Public Health. 2018;26(3):183-9.

74. Kolt GS, McEvoy JF. Adherence to rehabilitation in patients with low back pain. Man Ther. 2003;8(2):110-6.

75. Ilvig PM, Bredahl TVG, Justesen JB, Jones D, Lundgaard JB, Sogaard K, Christensen JR. Attendance barriers experienced by female health care workers voluntarily participating in a multi-component health promotion programme at the workplace. BMC Public Health. 2018;18(1):1340.

\section{Publisher's Note}

Springer Nature remains neutral with regard to jurisdictional claims in published maps and institutional affiliations.

\section{Ready to submit your research? Choose BMC and benefit from:}

- fast, convenient online submission

- thorough peer review by experienced researchers in your field

- rapid publication on acceptance

- support for research data, including large and complex data types

- gold Open Access which fosters wider collaboration and increased citations

- maximum visibility for your research: over $100 \mathrm{M}$ website views per year

At BMC, research is always in progress.

Learn more biomedcentral.com/submissions 